TP Periodica Polytechnica

Mechanical Engineering

62(2), pp. 165-172, 2018

https://doi.org/10.3311/PPme.11847

Creative Commons Attribution (i)

RESEARCH ARTICLE

\section{A Comparative Evaluation of Predictive Models of the Flat Rolling Process}

\author{
Máté Szücs $^{1 *}$, György Krállics ${ }^{1}$, John Lenard ${ }^{2}$
}

Received 19 December 2017; accepted after revision 29 January 2018

\begin{abstract}
The predictive abilities of several mathematical models of the cold, flat rolling process are tested by comparing their predictions to experimental measurements. The models include an empirical model, a one-dimensional model, a finite element model and an upper bound model. The coefficient of friction and the friction factor are first determined by the inverse approach, using the model deemed to be the most comprehensive. The effects of including or excluding an account of roll flattening, using elastic-plastic or rigid-plastic strips, and constant or velocity dependent coefficients of friction or friction factors are examined.
\end{abstract}

\section{Keywords}

flat rolling, mathematical models, coefficient of friction, friction factor

\footnotetext{
${ }^{1}$ Institute of Physical Metallurgy, Metal forming and Nanotechnology, Faculty of Materials Science and Engineering, University of Miskolc, H-3515 Miskolc-Egyetemváros, Hungary

${ }^{2}$ Department of Mechanical and Mechatronics Engineering, Faculty of Engineering, University of Waterloo,

200 University Avenue West Waterloo, ON, Canada

*Corresponding author, e-mail: femszmat@uni-miskolc.hu
}

\section{Introduction}

The success of a mathematical model is judged by the consistency and the accuracy of its ability to predict the variables in the rolling process. Usually these include the roll separating force and the roll torque, determined in carefully controlled experiments. Of the two criteria mentioned above, consistency of the predictive ability is the more important, since sometime accurate predictions are essentially useless. There are many modelling methods published in the technical literature that allows to study the flat rolling process like the empirical models, the one-dimensional models, the upper-bound models and the finite element analysis computing numerous parameters.

The empirical model presented by Schey [1] calculates the roll separating force by adjusting the compression of the strip to account for interfacial friction and the relative motion between the roll and the strip. The Hitchcock formula is used for taking into account the roll deformation and it requires an iterative approach. The rolled strip is modelled as rigid - ideally plastic material with isotropic hardening behaviour.

The one-dimensional model assumes the presence of plane strain flow, the homogeneous compression to predict the rolling force and torque. For the Bland and Ford's model is widespread to study the cold rolling process [2] The model requires to make several assumptions and simplifications reducing the complexities and allowing the closed form integration of the equation of equilibrium. In the model proposed by Roychoudhuri and Lenard [3] the flattening of the work-roll is taken into account using the two-dimensional theory of elasticity. The strip behaves like an elastic-plastic material which also added a further element of reality to the analysis. In the above mentioned models the coefficient of friction is treated as constant continuously during the rolling process.

The upper-bound approach that predict the power required for the steady-state process was also used in the analysis of the flat rolling process [4]. In most treatments the rolls are taken to be rigid and the rolled strips are rigid-ideally plastic, the friction factor is employed constant.

Finite-element method provides the opportunity to exam the flat rolling process in details thus numerous applications 
of the technique are available in the technical literature. A two-dimensional finite element model was presented by Dvorkin et al. [5] in which rigid - viscoplastic strips and the friction coefficient are considered. A three-dimensional finite element model developed by Jiang et al. [6] predicts the roll separating forces and the roll torques very well. In the model the workpiece behaves mechanically like a rigid - plastic material. Pins were embedded in the work roll to measure the frictional stress and the roll pressure between rolls and strip. Li and Kobayashi proposed a model which considers the relative velocity dependent coefficient of friction [7]. Shangwu et al studied the effects of both rigid and elastic rolls in details and they combined a three-dimensional finite element model with the boundary element method [8]. The behaviour of the rigidplastic rolled strip was taken into account and the boundary element approach was used to calculate the deformation and the deflection of the work roll. In the study of [9] a similar approach was followed in presenting a two-dimensional analysis of the flat rolling process and the calculated results were compared with the experimental data of frictional and normal stress measured by Al Salehi et al. [10].

A combination of the finite element method and fuzzy set theory presented by Dixit and Dixit to analyze the flat rolling process [11]. Wanheim and Bay's model [12] and Hitchcock's formula [13] were used to account for frictional events and the flattening of the work rolls. Material properties and the coefficients of friction were treated as fuzzy parameters. The predicted values of the roll force and the roll torque, obtained with either elastic or rigid rolls, were compared to the data of Shida and Awazuhara [14]. Gudur and Dixit [15] combined neural networks and the finite element method to study the cold, flat rolling process. They considered rigid - plastic materials and used a constant coefficient of friction, following Coulomb's model. Roll flattening was modelled by Hitchcock's equation. The linking of the two methods reduced the number of iterations, required by the FE model. Bézi et al. presented a finite-element model that takes into account the elastic flattening of the rolls, the elastic-plastic strips and the velocity dependent coefficient of friction, details of the numerical model and the computational results are published in [16]. Some papers with dealing with evaluation of force and torque models where local parameters of cold rolling were determined and the reliability of the models were also compared $[17,18]$.

The dependence of the predictive abilities of the models of the flat rolling process on the models themselves. First, the coefficient of friction and the friction factor were obtained by inverse analysis, using the most complex model. It is hypothesized that the FE model of Bézi et al. accounting for the flattening of the work roll, elastic-plastic rolled strip and a coefficient of friction or the friction factor that depend on the relative velocity $(\Delta v)$ will give the their most reliable magnitudes. Eq. (1) and (2) indicate the functional relationships of the coefficient of friction and the friction factor, as dependent on $\Delta v$, respectively:

$$
\mu=\mu_{0} \frac{2}{\pi} \tan ^{-1} \frac{\Delta v}{C}
$$

and

$$
m=m_{0} \frac{2}{\pi} \tan ^{-1} \frac{\Delta v}{C}
$$

where the terms $\mu_{0}$ and $m_{0}$ are multipliers. The magnitude of the constants $C$ depends on the roll velocity according to $C=\frac{v_{\text {roll }}}{20}$ where the velocity of the roll is in $\mathrm{m} / \mathrm{s}$.

Both the coefficient of friction and the friction factor are chosen such that the roll separating forces and the roll torques are all computed accurately and the difference between the predictions and the experimental data of Lenard [19] is minimized. In a separate set of similar calculations, the friction factor is also determined. The multipliers of the coefficient of friction and the friction factor, $\mu_{0}$ and $m_{0}$, thus determined, are shown in Fig. 1, as functions of the reduction and the ratio of the roll and the exit velocities.

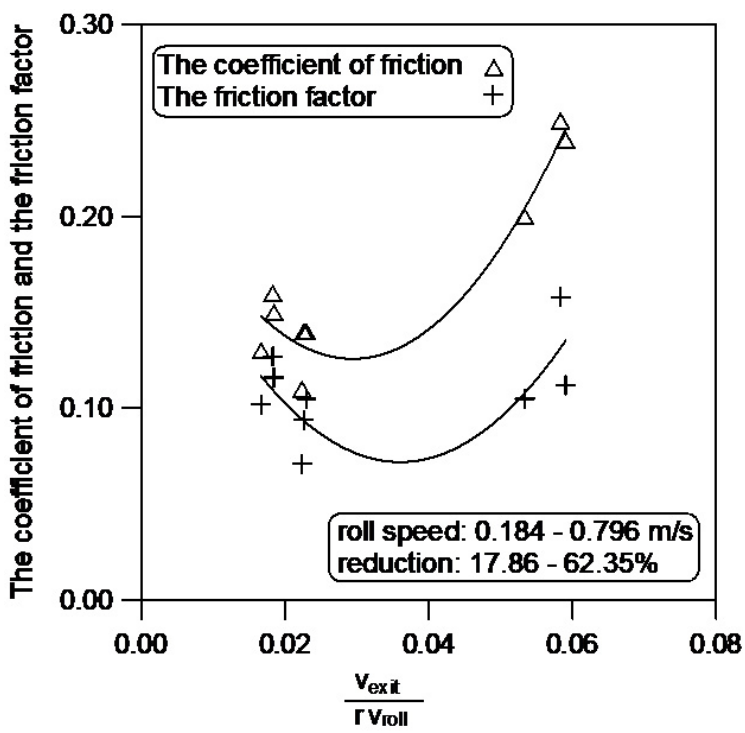

Fig. 1 The multipliers of the coefficient of friction and the friction factor, determined using the FEM and the inverse approach [19]

The coefficient of friction and the friction factor are known to depend on the relative velocity between the roll and the rolled strip and the reduction in a similar manner: both drop as the relative velocity and the reduction increase. The effect of the increasing relative velocity is due to the increasing amount of lubricant drawn into the contact zone while the effect of the increasing reduction is felt through the increasing viscosity of the lubricant. Since no sufficient data points are shown, these trends are not discernible in Fig. 1.

The dependence of the measured roll separating forces and the roll torques on the reduction and on the velocity of the work roll are shown in Fig. 2 and Fig. 3, respectively. 


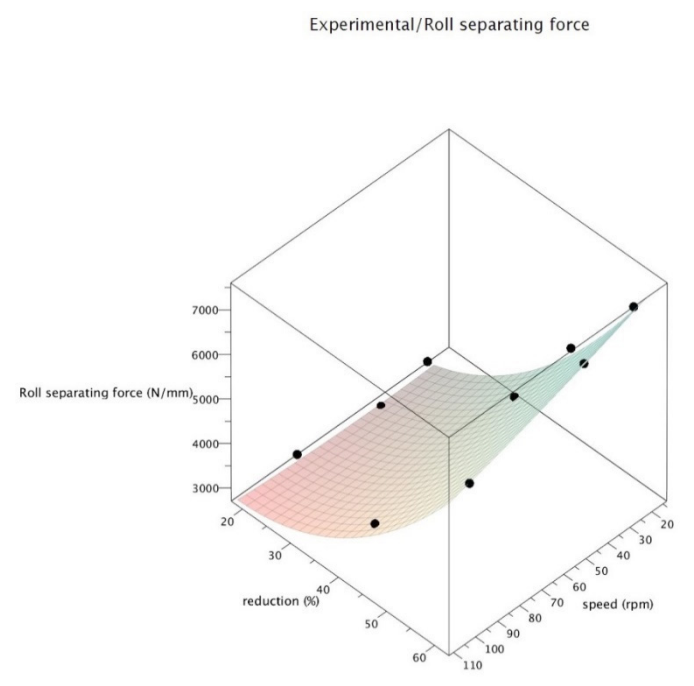

Fig. 2 The dependence of the roll separating force on the speed of the roll and on the reduction

Experimental/Torque

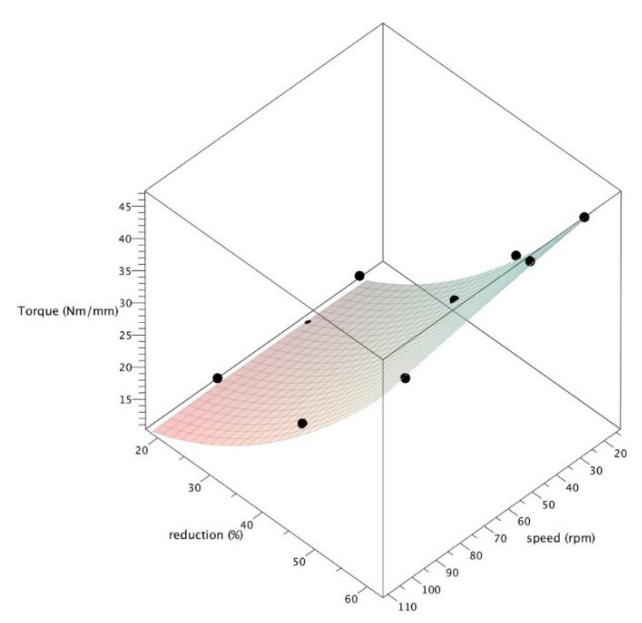

Fig. 3 The dependence of the roll torque on the speed of the roll and on the reduction

The equations of the surfaces shown above have been determined using multi-dimensional, non-linear regression analysis. Eq. (3) gives the roll force, with $\mathrm{R}^{2}=0.985$ while Eq. (4) indicates the roll torque, where $\mathrm{R}^{2}=0.995$. The reduction in $\%$ is designated by $r$ and the roll velocity in rpm, by $n$.

$$
F_{r}=2355.81+0.083 n+6.093 r+0.046 n^{2}+1.285 r^{2}-0.342 n r .
$$

and

$$
\begin{aligned}
M= & 5.85-0.00285 n+0.16 r+2.607 \cdot 10^{-5} n^{2}+0.0078 r^{2} \\
& -7.974 \cdot 10^{-4} n r .
\end{aligned}
$$

\section{The mathematical models and material characteristics}

Four numerical models were tested in the present study. In the first instance an empirical model was employed, the second is a simplified 1D model. The third model includes the upperbound (UBET) theory and in the last case, an advanced finite element model (FEM) was used.

For the numerical computations, the workpiece is defined as a homogeneous and isotropic hardening material. To describe the hardening property of material the true stress-strain curve of the alloy, obtained in isothermal compression test at room temperature. The metal's strength is essentially independent of the rate of strain. The true stress-strain curve of the alloy, is closely approximated to the relation $\sigma=270.8(1+77.7 \varepsilon)^{0.143} \mathrm{MPa}$.

During calculations, in the UBET and 1D slab models the flow stress depends on strain calculated from reduction of the workpiece and the roll is taken into account as rigid- or elastic body. The radius of the work roll, flattened by the loads, is designated by $R^{\prime}$ (expressed by Hitchcock's equation [13], Eq. (5)):

$$
R^{\prime}=R\left[1+\frac{16\left(1-v^{2}\right)}{\pi E} \cdot \frac{F_{r o l l}}{b \Delta h}\right]
$$

where $R$ is the radius of the unloaded work roll, $b$ is the width of rolled strip, $\Delta h=h_{\text {entry }}-h_{\text {exit }}$ and $F_{\text {roll }}$ is the rolling force.

For making predictive calculations two different frictional models were introduced and implemented into the 1D slab-, UBET and FEM models. The first is the Amonton and Coulomb frictional law (Eq. (6)) stating that that the interfacial shear stress $(\tau)$ is directly proportional to local normal pressure $p$.

$$
\tau=\mu \cdot p
$$

The frictional law proposed by Kudo describes the relationship (Eq. (7)) between the interfacial shear stress and the flow stress as

$$
\tau=m \frac{k_{f}}{\sqrt{3}}, \quad 0 \leq m \leq 1
$$

where the friction factor $m$ is given as the ratio of the interfacial shear stress and the yield strength in pure shear of the softer material in the contact. For perfect lubrication $m=0$ and sticking conditions occur when $m=1$. In both cases the coefficient of friction or the friction factor depend on the relative velocity as mentioned above.

\subsection{Material and the samples}

The empirical model proposed by Schey [1] describes the relationship between the roll separating force per unit width $\left(F_{r w}\right)$, the average flow strength of the rolled metal $\left(k_{f m}\right)$, the projected contact length $(L)$, and the pressure intensification factor $\left(Q_{p}\right)$. The multiplier of 1.15 is applied to account for the shape factor, the friction and a correction for the plane-strain flow in the roll gap. The model is written as (Eq. (8)):

$$
F_{r w}=1.15 \cdot Q_{p} \cdot k_{f m} \cdot L
$$

For the empirical model the Coulomb frictional law was introduced. 


\subsection{Material and the samples}

In the simplified model the equilibrium of the forces acting on a $d x$ wide volume element inside the workpiece is formulated, using the planes remaining planes assumption. The roll is assumed to be rigid and the rolled strip is taken to be rigid-plastic and isotropic. In the numerical solution, considering the material flow strength and the frictional stress, the equation of equilibrium (Eq. (9)):

$$
\frac{d \sigma}{d x}+\left(\frac{4}{\sqrt{3}} k_{f} \tan \alpha(x) \mp 2 \tau\left(\tan \alpha^{2}(x)+1\right)\right) \frac{1}{h(x)}=0
$$

was employed where $\sigma$ is the stress in rolling direction, $\alpha$ is the angle in the roll gap, $h$ is the actual thickness of the workpiece.

\subsection{UBET model}

The upper bound theorem proposed by Avitzur [4] formulates that among all kinematically admissible strain rate fields the actual one minimizes the expression (Eq. (10)):

$$
J^{*}=\int_{V} k_{f} \bar{\xi} d V+\int_{A_{\Gamma}} \tau|\Delta v| d A_{\Gamma}-\int_{A_{i}} T_{i} v_{i}
$$

where $J^{*}$ is the external force, the first integral gives the power required for the internal deformation, the second evaluates power generated by shearing along the internal surfaces of velocity discontinuity, the third accounts for power supplied by body tractions over the surface. It is required that velocity field satisfies the constancy of volume and the boundary conditions. In addition, the concept of velocity discontinuities is also needed to be clarify. During the numerical solution, minimum of the sum of three distinct components $J^{*}=\dot{W}_{i}+\dot{W}_{S}+\dot{W}_{f}$ is found. To analyse the rolling process these are as follows (Eq. (11), (12), (13)):

$$
\dot{W}_{i}=\frac{2}{\sqrt{3}} k_{f} v_{\text {roll }} h_{\text {exit }} \ln \frac{h_{\text {entry }}}{h_{\text {exit }}}
$$

is the power required for the internal deformation, where $v_{\text {roll }}$ is the roll velocity, $h_{\text {entry }}$ and $h_{\text {exit }}$ respectively are the initial- and final thickness of the workpiece.

$$
\dot{W}_{S}=\frac{2}{\sqrt{3}} k_{f} v_{\text {roll }} h_{\text {exit }}\left(\frac{1}{4} \sqrt{\frac{h_{\text {exit }}}{R}} \sqrt{\frac{h_{\text {entry }}}{h_{\text {exit }}}-1}\right)
$$

is the power required for the shearing along internal surfaces of velocity discontinuity.

$$
\dot{W}_{i}=\frac{2}{\sqrt{3}} k_{f} v_{\text {roll }} h_{\text {exit }}\left(\frac{m}{\sqrt{h_{\text {exit }} / R}} \sqrt{\frac{h_{\text {entry }}}{h_{\text {exit }}}-1}-\tan ^{-1} \sqrt{\frac{h_{\text {entry }}}{h_{\text {exit }}}-1}\right)
$$

is the power required for the friction between workpiece and roll.

\subsection{The finite element model}

Because of the symmetry exists in the rolling the finite element model includes only one roll and half of the rolled strip. Numerical calculations were made using MSC Marc finite element software for computational modelling of the forming process. Two types of models were established. In the first one the roll is substituted as a rigid body.

In the second model the roll is defined as an elastic body with its Young's modulus and Poisson's ratio E=210 GPa, and $v=0.3$, respectively. Fig 4 shows the finite element mesh used for the simulation of the rolling process. The meshes contain two-dimensional Quad (4) elements, 7401 in the roll and 3600 in the half-strip. The strip is modelled as an isotropic elasticplastic material during the process. The isotropic hardening behaviour of rolled strip described by true stress - strain equation of the alloy mentioned above. The rolling models used in the calculations and their details are given in Table 1.

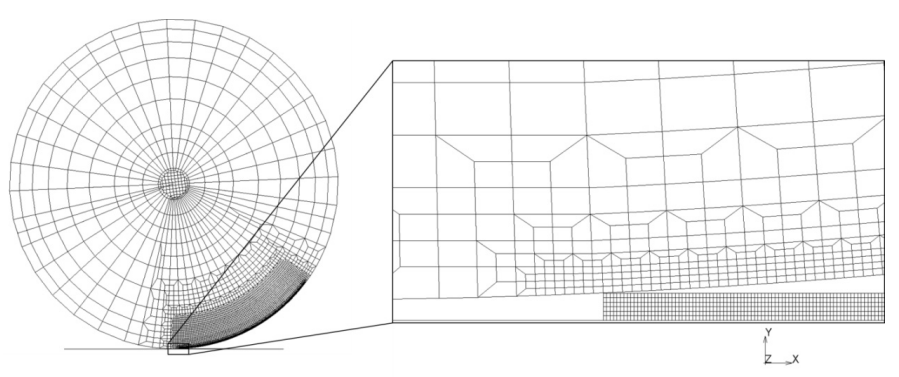

Fig. 4 2D finite element mesh used for the simulation of the rolling process

\section{Experiments}

\subsection{Equipment}

For the comparison to the predictions of the models the results of experimental strip rolling made by Lenard [19]. The details of these are described here briefly for completeness. All experiments were conducted on a STANAT 2-high rolling mill driven by a 12 $\mathrm{kW}$, constant torque, DC motor, providing rolling speeds up to $1100 \mathrm{~mm} / \mathrm{s}$ surface velocity. The work rolls are made of L3 tool steel, hardened to Shore 90 . The rolls are of $150 \mathrm{~mm}$ diameter and $203 \mathrm{~mm}$ face width. The roll surface roughness is $R_{a}=0.3 \mathrm{~mm}$. The mill is instrumented with two force transducers, placed over the bearing blocks of the top work roll and two torque transducers, placed in the drive spindles. The signals of two diodes, placed $50.68 \mathrm{~mm}$ apart at the exit, lead to the exit velocity of the strips and hence, to the forward slip. A tachometer is used to monitor the roll speed. Data are collected using a personal computer, a DASH $16 \mathrm{~A} / \mathrm{D}$ board and a National Instrument signal conditioner.

\subsection{Material and the samples}

6061-T6 aluminum alloy strips of $1.6 \mathrm{~mm}$ thickness, $25 \mathrm{~mm}$ width and $300 \mathrm{~mm}$ length are rolled. The surface roughness of the strips before rolling is $\mathrm{R}_{\mathrm{a}}=0.2 \mathrm{~mm}$ in both the rolling and in the transverse direction. The chemical composition is given in Table 2. 
Table 1 The models used in the study

\begin{tabular}{|c|c|c|}
\hline & FRICTION & MODEL \\
\hline A.1 & $\mu=f(\Delta v)$ & FEM, elastic roll, elastic-plastic rolled material \\
\hline A. 2 & $\mu=f(\Delta v)$ & FEM, rigid roll, elastic-plastic rolled material \\
\hline A. 3 & $\mu=f(\Delta v)$ & $\begin{array}{l}\text { 1D Slab analysis, elastic roll, rigid-plastic } \\
\text { rolled material }\end{array}$ \\
\hline A. 4 & $\mu=f(\Delta v)$ & $\begin{array}{l}\text { 1D Slab analysis, rigid roll, rigid-plastic } \\
\text { rolled material }\end{array}$ \\
\hline B.1 & $m=f(\Delta v)$ & FEM, elastic roll, elastic-plastic rolled material \\
\hline B. 2 & $m=f(\Delta v)$ & FEM, rigid roll, elastic-plastic rolled material \\
\hline B. 3 & $m=f(\Delta v)$ & $\begin{array}{l}\text { UBET (virtual velocities), rigid roll, } \\
\text { rigid-plastic material }\end{array}$ \\
\hline B.4 & $m=f(\Delta v)$ & $\begin{array}{l}\text { UBET (virtual velocities), elastic roll, } \\
\text { rigid-plastic material }\end{array}$ \\
\hline B.5 & $m=f(\Delta v)$ & $\begin{array}{l}\text { 1D Slab analysis, rigid roll, rigid-plastic } \\
\text { rolled material }\end{array}$ \\
\hline B.6 & $m=f(\Delta v)$ & $\begin{array}{l}1 \mathrm{D} \text { Slab analysis, elastic roll, rigid-plastic } \\
\text { rolled material }\end{array}$ \\
\hline C.1 & $\mu$ is const. & $\begin{array}{l}1 \mathrm{D} \text { Slab analysis, elastic roll, rigid-plastic } \\
\text { rolled material }\end{array}$ \\
\hline C. 2 & $\mu$ is const. & $\begin{array}{l}\text { 1D Slab analysis, rigid roll, rigid-plastic } \\
\text { rolled material }\end{array}$ \\
\hline C. 3 & $\mu$ is const. & Empirical model, rigid rolls, rigid-plastic material \\
\hline C. 4 & $\mu$ is const. & FEM, elastic roll, elastic-plastic rolled material \\
\hline C.5 & $\mu$ is const. & FEM, rigid roll, elastic-plastic rolled material \\
\hline D.1 & $m$ is const. & $\begin{array}{l}\text { 1D Slab analysis, rigid roll, rigid-plastic } \\
\text { rolled material }\end{array}$ \\
\hline D.2 & $m$ is const. & $\begin{array}{l}\text { 1D Slab analysis, elastic roll, rigid-plastic } \\
\text { rolled material }\end{array}$ \\
\hline D. 3 & $m$ is const. & $\begin{array}{l}\text { UBET (virtual velocities), rigid roll, rigid-plastic } \\
\text { rolled material }\end{array}$ \\
\hline D.4 & $m$ is const. & $\begin{array}{l}\text { UBET (virtual velocities), elastic roll, rigid-plastic } \\
\text { rolled material }\end{array}$ \\
\hline D.5 & $m$ is const. & FEM elastic roll, elastic-plastic rolled material \\
\hline D.6 & $m$ is const. & FEM rigid roll, elastic-plastic rolled material \\
\hline
\end{tabular}

Table 2 The chemical composition of the 6061-T6 alloy

\begin{tabular}{ccccc}
\hline $\mathrm{Mg}$ & $\mathrm{Si}$ & $\mathrm{Cu}$ & $\mathrm{Cr}$ & $\mathrm{Al}$ \\
\hline 1.0 & 0.6 & 0.3 & 0.2 & rest \\
\hline
\end{tabular}

\subsection{Lubricant}

A light, paraffinic mineral seal oil is used with $5 \% \mathrm{v} / \mathrm{v}$ oleyl alcohol added as the boundary additive. The kinematic viscosity of the oil is $4.4 \mathrm{~mm}^{2} / \mathrm{s}$ and $40^{\circ} \mathrm{C}$ and $1.53 \mathrm{~mm}^{2} / \mathrm{s}$ at $100^{\circ} \mathrm{C}$. Its density at $40^{\circ} \mathrm{C}$ is $850 \mathrm{~kg} / \mathrm{m}^{3}$. The temperature-viscosity parameter is calculated as $0.0176{ }^{\circ} \mathrm{C}-1$. Earlier work with this lubricant, while rolling commercially pure aluminum strips using rolls of 0.18 $m m R_{a}$ roughness and placing ten drops of the lubricant on each side, indicated that under most circumstances sufficient amounts of oil were entrained and were able to cause decreasing loads on the rolling mill as the speeds were increased (Lenard [19]).

\subsection{Procedure}

Acetone is used to clean the work rolls and strips before each experimental rolling pass. The same amount of lubricant is spread evenly using a clean brush on both side of the strip. The mill speed, the roll gap distance and the data acquisition system are set up. After each rolling the strips are wiped clean and the thickness is measured.

\section{Results}

These errors have been determined by comparing the surfaces, shown in Fig. 2 and 3, depicting the dependence of the roll separating forces and the roll torques on the roll velocity and the reduction, and surfaces, obtained in a similar fashion, for the computed roll forces and torques. The calculations are given by Eq. (14) and (15), where $f_{\text {model }}$ stands for the surfaces of the predictions and $f_{\text {data }}$ designates the surfaces of the measurements. The errors, as determined by Eq. (15), are indicated in Fig. $5-8$.

$$
\begin{gathered}
s(x, y)=\sqrt{\left[\left(f_{\bmod e l}-f_{\text {data }}\right) / f_{\text {data }}\right]^{2}} . \\
\operatorname{error}(\%)=100 \cdot \frac{1}{x_{\max }-x} \int_{x_{\min }}^{x_{\max } y_{\min }} s(x, y) d x d y .
\end{gathered}
$$

\subsection{Comparison of the predictions}

The results of the computations, using the empirical, 1D, UBET and finite element models are shown in the bar charts of Fig. 5, 6, 7, and 8. The roll separating forces in Fig. 5 and the roll torques for both rolls in Fig. 6. In both figures, the best predictions resulted when the finite element method was used, the rolls were taken to remain rigid and the friction factor was allowed to vary from entry to the exit as a function of the relative velocities between the roll and the rolled strip. The results using the 1D slab method, Hitchcock's formula and keeping the friction factor constant in the pass are mixed; the roll force was predicted quite well while the roll torque was not. Simplifying the 1D method further by introducing rigid rolls resulted in the opposite: the roll force prediction worsened, and the torque calculations improved. The least usable predictions were obtained when the upper-bound theory was employed.

Calculations using the coefficient of friction are shown in Fig. 7 and 8; the roll forces are given in Fig. 7 and the roll torques in Fig. 8. As before, the best predictions resulted when the rigid rolls replaced the elastically deforming ones. The next is the slab method.

However, in this step the deformation of the rolls was determined by the use of Hooke's law in two-dimensions (Roychoudhuri and Lenard [3]). Further, the coefficient of friction was taken to remain constant, independent of the relative velocities of the roll and the stip. These results were followed by the 1D approach, rigid rolls and constant coefficient of friction and finally by the empirical technique, using rigid rolls, rigid-plastic strips and constant coefficients of friction. 


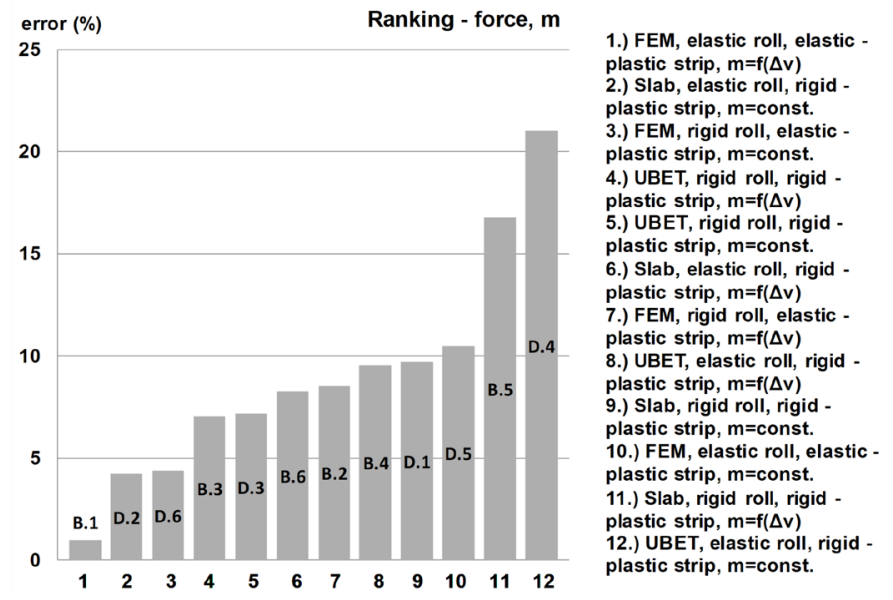

Fig. 5 The errors between the measurements and the predictions of the roll separating force - friction factor

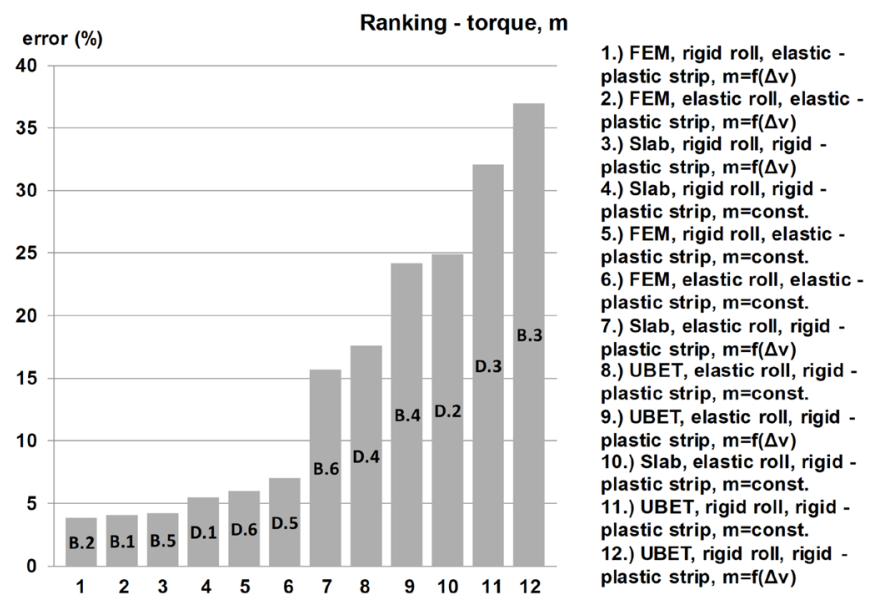

Fig. 6 The percent differences between the measurements and the predictions of the roll torque - friction factor

\section{Discussion}

The information presented in Fig. 5 to Fig. 8 may be used to consider the effects of several characteristics to the ability of a mathematical model to predict experimental data. The characteristics considered are the deformation of the work roll during the pass; the description of the resistance to deformation of the rolled material and the variation of the coefficient of friction or the friction factor in the contact zone. In each of the figures the percent differences between the measurements and the predictions are shown on the ordinate.

In Fig. 5 and Fig. 6 the errors of the roll force increased somewhat and the errors of the roll torque remained unchanged when rigid rolls were used in the FE approach, instead of elastically deforming rolls. This may be explained by looking at how both the forces and the torques are computed. Both are obtained by considering them as boundary conditions and the summation of the components of the forces along the roll surface leads to them. As shown by Bézi et al. [16], the contact length with the rigid rolls is shorter than that with the elastic rolls. The roll pressures are higher, however, while the roll gap

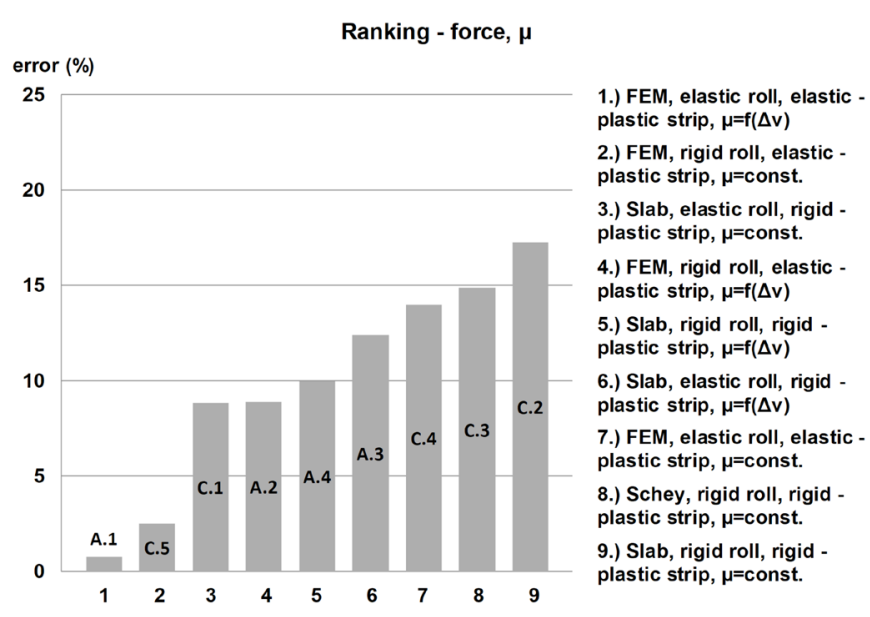

Fig. 7 The errors between the measurements and the predictions of the roll separating force - coefficient of friction

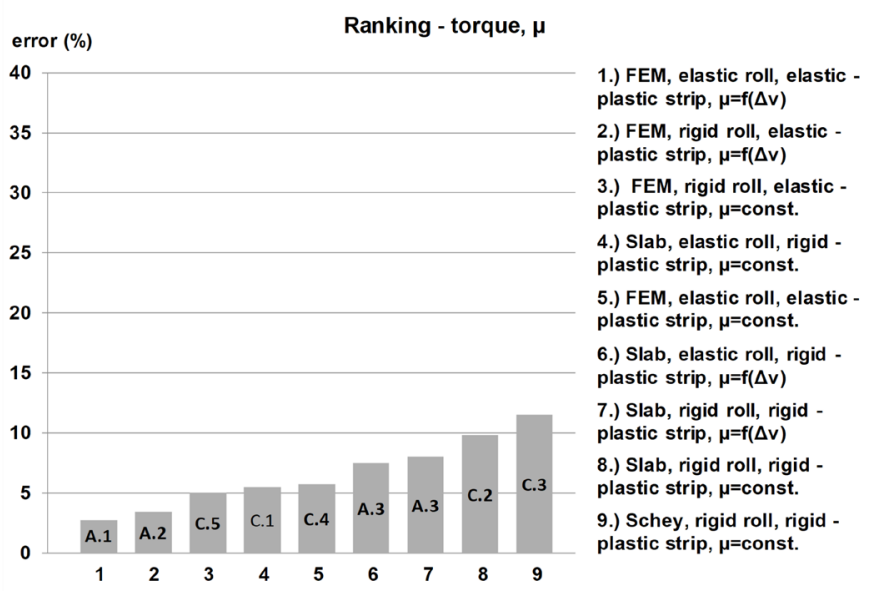

Fig. 8 The percent differences between the measurements and the predictions of the roll torque - coefficient of friction

remains unchanged. Rolling with the elastically flattening rolls will result in a smaller reduction. The changes of the contact length affect the integration less than the increase of the roll pressures so the forces are indicated to rise while the torques, affected mostly by the interfacial shearing forces, change little.

The results obtained with the 1D method, Hitchcock's formula, elastic-plastic strips and constant friction factor are not surprising. Both the roll force and the roll torque are calculated reasonably well.

The kinematically admissible velocity field, used in the upper bound approach, was derived based on the incompressibility of the plastically deforming material as well as retaining the homogeneity of the compression during the rolling process, following Kolmogorov [20] and Kolmogorov et al. [21]. The boundary conditions of the velocity field were also satisfied. The velocity at the neutral cross section was determined by minimizing the power. The approach, however, is designed to yield conservative results, always over-predicting the experimental data and that is, in fact, shown in the figures.

The effect of the coefficient of friction on the predictions is 
shown in Fig. 7 and Fig. 8, giving the roll separating forces and the roll torques, respectively. The order of the quality of the predictions is very much like the ones obtained with the friction factor. Replacing the elastic rolls with the rigid rolls results in a drop of predictive ability as does the use of the coefficient of friction as a constant. The upper bound approach again over predicted the data.

One-to-one comparisons are also possible. Consider the roll separating force first. The errors, when using the FEM with rigid rolls, elastic-plastic strips and either the velocity-dependent friction factor or the coefficient of friction, are practically the same. The error, using the 1D model with Hitchcock's formula and a constant friction factor was found to be less than half that when rigid rolls were employed. Similar observations are arrived at when constant coefficients of friction are used in the calculations.

Calculating the roll torques with the FEM, rigid rolls, and the errors with either the friction factor or the coefficient of friction are similar, as with the roll force. The numbers obtained with the 1D slab method are now quite different, though. Constant friction factor and Hitchcock's formula gave the highest error so far, almost $23 \%$. Replacing the equation with $2 \mathrm{D}$ Hooke's law cut the error to just under 6\%. Employing the constant coefficient of friction indicated that careful accounting for the flattening of the rolls lowers the error.

The empirical model's errors were considerably higher than those mentioned above.

\section{Conclusions}

The effects of rigid or elastic rolls, homogeneous compression or 2D stress and strain distribution, constant or varying coefficient of friction or friction factor on the predictive abilities of mathematical models of the flat rolling process were examined. While the predictive abilities increased as the complexities of the models increased, the changes were not prohibitively large. The largest effect resulted when the velocity-dependent coefficient of friction or the friction factor were replaced by their constant values. Even these changes, however, were not excessive. The best recommendation in the choice of a model is to match its complexities to the engineer's requirements. In general, the guiding principle should be to use the simplest model possible, as long as its predictions are consistent.

\section{Acknowledgement}

The described article was carried out as part of the EFOP3.6.1- 16-2016-00011 "Younger and Renewing University - Innovative Knowledge City - institutional development of the University of Miskolc aiming at intelligent specialisation" project implemented in the framework of the Szechenyi 2020 program. The realization of this project is supported by the "European Union, co-financed by the European Social Fund." and the "ALUFORM GINOP 2.2.1-15-2016-00018" project.

\section{References}

[1] Schey, J. A. "9-7-5 Forces and Power Requirements." In: Introduction to Manufacturing Processes. (pp. 368-370), 3rd edition, McGraw-Hill, New York, 2000.

[2] Bland, D.R., Ford, H. "The Calculation of Roll Force and Torque in Cold Strip Rolling with Tensions." Proceedings of the Institution of Mechanical Engineers. 139, pp. 144-133. 1948.

https://doi.org/10.1243/PIME_PROC_1948_159_015_02

[3] Roychoudhury, R., Lenard, J. G. "A Mathematical Model for Cold Rolling - Experimental Substantiation." In: Proceedings of the 1st International Conference on Technology of Plasticity, Tokyo, pp. 11381143. 1984

[4] Avitzur, B. "Metal Forming: Processes and Analysis." McGraw-Hill, Inc., New York, 1968.

[5] Dvorkin, E. N., Goldschmit, M. B., Cavaliere, M. A., Amenta, P. M., Marini, O., Stroppiana, W. "2D Finite Element Parametric Studies of The Flat-Rolling Process." Journal of Materials Processing Technology. 68, pp. 99-107. 1997.

https://doi.org/10.1016/S0924-0136(96)00027-1

[6] Jiang, Z. Y., Tieu, A. K., Zhang, X. M., Lu, C., Sun, W. H. "Finite Element Simulation of Cold Rolling of Thin Strip." Journal of Materials Processing Technology. 140, pp. 542-547. 2003. https://doi.org/10.1016/S0924-0136(03)00832-X

[7] Li, G., Kobayashi, S. "Rigid-Plastic Finite-Element Analysis of Plane Strain Rolling." Journal of Engineering for Industry. 104, pp. 33-64. 1982. https://doi.org/10.1115/1.3185797

[8] Shangwu, X., Rodrigues, J. M. C., Martins, P. A. F. Three-dimensional Simulation of Flat Rolling Through a Combined Finite ElementBoundary Element Approach." Finite Elements in Analysis and Design. 32, pp. 221-233. 1999.

https://doi.org/10.1016/S0168-874X(99)00005-0

[9] Shangwu, X., Rodrigues, J. M. C., Martins, P. A. F. "Simulation of Plane Strain Rolling Through a Combined Finite Element Boundary Element Approach." Journal of Materials Processing Technology. 96, pp. 173181. 1999.

https://doi.org/10.1016/S0924-0136(99)00342-8

[10] Al-Salehi, F. A. K., Firbank, T. C., Lancaster, P. R. "An Experimental Determination of the Roll Pressure Distribution in Cold Rolling." International Journal of Mechanical Sciences. 15, pp. 693-710. 1973. https://doi.org/10.1016/0020-7403(73)90049-0

[11] Dixit, U. S., Dixit, P. M. "A Finite Element Analysis of Flat Rolling and Application of Fuzzy Set Theory. International Journal of Machine Tools and Manufacture. 36(8), pp. 947-969. 1996. https://doi.org/10.1016/0890-6955(95)00099-2

[12] Wanheim, T., Bay, N. "A Model for Friction in Metal Forming Processes." Annals of the CIRP. 27, pp. 189-194. 1978.

[13] Hitchcock, J. H. "Roll Neck Bearings. App. I." ASME, New York, 1935.

[14] Shida, S., Awazuhara, H. "Rolling Load and Torque in Cold Rolling." Journal of the Japan Society for Technology of Plasticity. 14, pp. 267278. 1973.

[15] Gudur, P. P., Dixit, U. S. "A Neural Network-Assisted Finite Element Analysis of Cold Flat Rolling." Engineering Applications of Artificial Intelligence. 21, pp. 43-52. 2008.

https://doi.org/10.1016/j.engappai.2016.10.001

[16] Lenard, J. G. "An Advanced Finite Element Model of the Flat, Cold Rolling Process." In: Primer on Flat Rolling. (pp. 113-123.) 2nd Edition, Elsevier, Oxford, 2013.

https://doi.org/10.1016/B978-0-08-099418-5.00006-8

[17] Roberts, W. L. "Cold Rolling of Steel." Marcel Dekker, Inc., New York, 1978. 
[18] Nascimento, H. L. F., Shigaki, Y., Santos, S. C., Hubinger, A. Z. "A study of the rolling load calculation models for flat cold rolling process." In: XXXVII Iberian Latin-American Congress on Computational Methods in Engineering, Brasil, 2016.

[19] Lenard, J. G. "The Effect of Roll Roughness on the Rolling Parameters During Cold Rolling of an Aluminum Alloy." Journal of Materials Processing Technology. 152(2), pp. 144-133. 2004.

https://doi.org/10.1016/j.jmatprotec.2004.03.026
[20] Kolmogorov, V. L. "A method for calculating the stress-strain state in the general boundary value problem of metal forming - part 1." International Journal of Solids and Structures. 36, pp. 1253-1262. 1999. https://doi.org/10.1016/S0020-7683(98)00011-0

[21] Kolmogorov, V. L., Spevak, L. F., Gorshkov, A. V. "A method for calculating the stress-strain state in the general boundary value problem of metal forming- part 2; impact of a bar against a rigid obstacle." International Journal of Solids and Structures. 36(9), pp. 1263-1275. 1999. https://doi.org/10.1016/S0020-7683(98)00012-2 